\title{
Stress reduction by Phochong chanting indexed by Thai Stress Test
}

\author{
Jidapa Kerdsurivong ${ }^{1}$, Jarasphol Rintra², Karnt Wongsuphasawat ${ }^{2}$, \\ Phakkharawat Sittiprapaporn ${ }^{1,3}$
}

${ }^{1}$ Researcher, Brain Science and Engineering Innovation Research Group, School of Anti-Aging and Regenerative Medicine, Mae Fah Luang University, Bangkok, Thailand, '2Lecturer, Department of Anti-Aging and Regenerative Medicine, School of Anti-Aging and Regenerative Medicine, Mae Fah Luang University, Bangkok, Thailand, ${ }^{3}$ Assistant Professor, Department of Anti-Aging and Regenerative Science, School of Anti-Aging and Regenerative Medicine, Mae Fah Luang University, Bangkok, Thailand

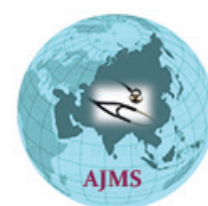

\section{A B S TR A C T}

Background: Stress is traditionally defined as either a bodily or mental tension resulting from factors that tend to alter an existent equilibrium or the process of appraising events of assessing potential responses, and of responses which may include not just physiological but also cognitive and behavioural changes. Aims and Objective: The purpose of this study was to examine the stress reduction after listening to Phochong chanting. Materials and Methods: Forty participants were participated in this study. They were divided into two groups; the control group who saw a spot on computer screen while listening to Phochong chanting for 10 minutes, and the target group who saw the Buddha image while listening to Phochong chanting for 10 minutes. The Thai Stress Test was used as a tool to examine the stress reduction. Frequency, percentage, mean, and standard deviation were used for descriptive data analysis. Paired sample t-test was also used to compare between before and after listening to Phochong chanting. Results: The percentage of participants in the target group who felt 'excellent mental health' was $20.0 \%$ and only $10 \%$ for the control one. The $55.0 \%$ in the target group felt 'normal mental health' while $45.0 \%$ was for the control one. About $25.0 \%$ of the target group felt 'mild stress' while $45.0 \%$ was in the control one. However, no participant showed 'sever stress (stressful)' in this study. The Thai Stress Test has adequate reliability, adequate construct validity, and sufficient discriminant power. Conclusion: By listening to Phochong chanting would help the stress level reduction.

Access this article online

Website:

http://nepjol.info/index.php/AJMS DOI: 10.3126/ajms.v10i5.22461 E-ISSN: 2091-0576

P-ISSN: 2467-9100

Key words: Stress; Thai Stress Test; Meditation; Chanting; Phochong

\section{INTRODUCTION}

According to the Webster's ninth new collegiate dictionary, ${ }^{1}$ stress is defined as a bodily or mental tension resulting from factors that tend to alter an existent equilibrium. A stress response is the compensatory reaction the body makes to the disturbance caused by the stressor. In addition, Taylor mentioned that stress is defined as the process of appraising events (as harmful, threatening, or challenging), of assessing potential responses, and of responses which may include not just physiological but also cognitive and behavioural changes. ${ }^{2}$
In 2012, Sani and colleagues stated that stress and its psychological manifestations were inherent in the human life. Both stress and its psychological manifestations were also a major source of concern in the modern-day society. 3,4 Some previous studies had been demonstrated that stress in individuals is defined as anything that disrupts the normal person's physical or mental wellbeing. It arises due to the inability of an individual to meet the demands made on him. A mild form of stress may manifest as a bad mood while an extreme one may lead to an act of violence, burnout or suicide. ${ }^{3,4}$ However, the overall impact of a stressor will

\section{Address for Correspondence:}

Dr. Phakkharawat Sittiprapaporn, Assistant Professor, Brain Science and Engineering Innovation Research Group, School of Anti-Aging and Regenerative Medicine, Mae Fah Luang University, Bangkok 10110, Thailand. Tel No: +662 6644361. Fax No: +662 6644362.

E-mail: wichian.sit@mfu.ac.th; Dr. Karnt Wongsuphasawat, Department of Anti-Aging and Regenerative Science,

School of Anti-Aging and Regenerative Medicine, Mae Fah Luang University, Bangkok, Thailand,

E-mail: karnt.won@mfu.ac.th 
depend on its features and the characteristics of those who have been affected. The perceived rather than the absolute quantities of a stressor determine its potential impact. ${ }^{4}$

Stress represents the wear and tear of the body. Stress can be positive or negative. Positive stress is named eustress and negative stress is distress. Eustress triggers the body alarm, and enhances attention, performance and creativity which has temporary effects only. On the other hand, the distress has negative effects on the body. ${ }^{3}$ However, chronic stress can have serious effects on human health and behavior. ${ }^{3}$ Stress is also known as a matter of perception, because not all are equally affected. ${ }^{3,4}$ Internal individual factors such as gender, age, and chronic illness as well as external individual factors named newly added experience from the environment such as education, occupation, and income have an influence on stress. ${ }^{5}$ Exploring the relationships, both of internal and external, of individual factors, is necessary. Both assessing our bodies, reacting to stress and how we think, feel and behave in stressful situation are increasingly attention. The emotional responses to stress may include such feelings an anxiety, irritability, anger, embarrassment, depression, and hospitality, respectively. ${ }^{6}$

Stress has been found to be associated with anxiety and depression,,${ }^{7,8}$ interpersonal conflict, ${ }^{9}$ sleep problems ${ }^{10}$ and lower academic and clinical performance. ${ }^{11}$ In 1956, Selye described on organism's physiological responses to stress and formulated the general adaptation syndrome (GAS), composed of three phases including alarm, resistance, and exhaustion, respectively. ${ }^{12}$ Thus, it is necessary to take into account the psycho-social-spiritual aspects of being human by mean of the interactions among all dimensions of humanness, especially the physical body and mind. ${ }^{13-15}$

Several Eastern methods have been used for balancing the dimensions of one's humanness, ${ }^{16}$ for instance, one such method is Buddhist mediation, which has been shown to be effective in treating mild to moderate hypertension. ${ }^{17}$ Engaging in Buddhist meditation cultivates concentration and positive mindfulness that can facilitate a decrease in the sense of suffering and an increase in a sense of calm. ${ }^{18}$ Positive mindfulness thus appears to stimulate the parasympathetic nervous system, which, in turn, leads to a decreased heart rate, dilation of the peripheral blood vessels and improved blood flow. ${ }^{19}$ These factors contribute to reduction in one's blood pressure..$^{20,21}$ Previous studies showed that meditation decreases systolic and diastolic blood pressure, ${ }^{22-26}$ heart rate, ${ }^{24,25}$ stress $^{22,23}$ and the use of antihypertensive medications ${ }^{26}$ respectively. Thus, the aim of this study was to investigate self-perceived stress among participants those who had listen to Phochong chanting at the School of Anti-Aging and Regenerative Medicine, Bangkok, Thailand. It was hoped that the chant would help participants to relief the stress level.

\section{MATERIALS AND METHODS}

\section{Participants}

A total of forty participants were participated in this study. They were equally divided into two groups; one was a control group (20 participants) and the other was the target one (20 participants). The mean age of participants was 35.85 years $(\mathrm{SD}=3.46)$ for both groups.

\section{Instruments}

The questionnaires used was the Thai Stress Test ${ }^{6}$. According to Phattharayuttawat's study ${ }^{6}$ the Thai Stress Test consists of 24 questions that described psychological reactions (both positive and negative) in relation to events occurring in daily life of Thai people. All 24 questions in the Thai Stress Test was used to assess one's feelings and thoughts (positive and negative) over the past month. Examples of the questions were: "Do you feel lonely?"; "Do you feel bored and discouraged about doing anything?"; "Do you feel proud about yourself?"; and, "Do you feel pleased about your life?", respectively. Possible responses to each questions were: "Never" = 0; "Sometimes" = 1; and "Often" = 3 . Responses to questions assessing negative feelings (items 1-12) and positive feelings (items 13-24) were separately summed, with both having a possible range of 0 to 36 . To obtain an index scores, results of the two scores were simultaneously compared to the Thai Stress Test matrix table. The index score obtained, according to the Thai Stress Test matrix table, was used to determine the individual's level of stress (good mental health, normal, mild stress or severe stress). Based on the Phattharayuttawat's study, ${ }^{6}$ the Thai Stress Test has both constructive validity and reliability: the total reliability coefficient for the Alpha, which was 0.84 , and value, of the two scales ranged from 0.83 to 0.86 . The total split half was 0.88 , with the Alpha ranging from 0.85 to 0.91 . Each question could be rated on a three-point scale: 'never', 'sometimes' and 'often'. The participants were asked to put a tick $(\sqrt{ })$ in the column corresponding to the feeling that has applied best to them after listening to Phochong chanting. To calculate scores, positive and negative scores were combined separately. Weights of 0,1 and 3 are assigned to represent 'never', 'sometimes' and 'often' respectively, then stress indicator was categorized by using the matrix table of the Thai Stress Test, shown in Table 1.

The four stress levels were divided into excellent mental health, normal mental health, mild stress, and Stressful, respectively. That is, all four stress levels were divided into four groups: one group with stress (people indicating severe stress (stressful); one group with mild stress (people indicating mild stress); one group with normal (people who have normal mental health); and the other without stress (people who have excellent mental health), respectively, shown in Table 2. 


\section{Procedures}

Participants were divided into two groups; the target group saw the Buddha image on the computer screen in front of them while listening to Phochong chanting for 10 minutes long and the other control group saw the spot on the computer screen in front of them while listening to Phochong chanting for 10 minutes long. Both groups did all activities at Brain Science and Engineering Innovation Research Unit, School of Anti-Aging and Regenerative Medicine, Mae Fah Luang University, Bangkok, Thailand. The procedures were as follows: (a) Step I: Focus group discussions were carried out by the authors to obtain qualitative information about sources of stress during the past months, (b) Step II: The questionnaires were sent to participants after listening to Phochong chanting.

The questionnaire consisted of two parts: (a) Part I: Demographic data and personal information including gender, age, and educational level, (b) Part II: Thai Stress Test questionnaire to measure stress levels. Participants were then asked to rate their stress level for each particular event ranking from $0=$ 'no stress at all' to $4=$ 'severely stressful'.

Prior to implementation, the study and its procedure were reviewed and approved by the Institutional Review Board (IRB) of the primary investigator's (PI) academic institution (Mae Fah Lung University, Thailand). All participants were informed about (a) the purpose of the study, (b) voluntary participation, (c) what study involvement entailed, (d) confidentiality and anonymity issues, and (e) the right to withdraw from the study anytime without repercussions, accordingly. All participants were given information about the study, and completed informed consent sent with the questionnaires. Both written and verbal consents to participate were also obtained from those agreeing to take part in the study.

\section{Data collection and analysis}

Descriptive statistics were used to describe the demographic data and stress levels, and mindfulness levels, respectively. Data were entered and analyzed using the statistical software. A comprehensive score was derived from the twenty four questions of the Thai Stress Test as an outcome variable. Descriptive statistics (mean, standard deviation, and percentages) were used for summarizing the outcome variables.

\section{RESULTS}

Data were collected from participants, shown in Table 3. A total of 40 participants participated in this study. They were equally divided into two groups; one was a control group (20 participants) and the other was the target one

\begin{tabular}{|c|c|c|c|c|c|}
\hline \multirow[t]{2}{*}{$\begin{array}{l}\text { Negative Scales } \\
\text { Score (Sum of Items 1-12) }\end{array}$} & \multicolumn{5}{|c|}{$\begin{array}{l}\text { Positive Scales Score } \\
\text { (Sum of Items 13-24) }\end{array}$} \\
\hline & $12-36$ & $9-11$ & $6-8$ & $3-5$ & $0-2$ \\
\hline $0-1$ & 1 & 2 & 3 & 4 & 5 \\
\hline $2-3$ & 2 & 3 & 4 & 5 & 6 \\
\hline $4-5$ & 3 & 4 & 5 & 6 & 7 \\
\hline $6-7$ & 4 & 5 & 6 & 7 & 8 \\
\hline $8-36$ & 5 & 6 & 7 & 8 & 9 \\
\hline
\end{tabular}

$\begin{aligned} & \text { Table 2: Distribution of the sample of the index } \\
& \text { of the Thai Stress Test }\end{aligned}$
\begin{tabular}{ll} 
Score Group & Stress Indicator (Level of Stress) \\
\hline 1 & Excellent Mental Health \\
$2,3,4$ & Normal Mental Health \\
5,6 & Mild Stress \\
$7,8,9$ & Stressful \\
\hline
\end{tabular}

\begin{tabular}{|c|c|c|c|c|}
\hline \multirow[t]{2}{*}{ Factors } & \multicolumn{2}{|c|}{$\begin{array}{c}\text { Control } \\
\text { Group }(n=20)\end{array}$} & \multicolumn{2}{|c|}{ Target Group $(n=20)$} \\
\hline & Number & Percent & Number & Percent \\
\hline \multicolumn{5}{|l|}{ Gender } \\
\hline Male & 1 & 5.00 & 3 & 15.00 \\
\hline Female & 19 & 95.00 & 17 & 85.00 \\
\hline \multicolumn{5}{|l|}{ Age } \\
\hline $\begin{array}{l}\text { Less than } \\
25 \text { years }\end{array}$ & 2 & 10.00 & 3 & 15.00 \\
\hline $26-30$ years & 4 & 20.00 & 5 & 25.00 \\
\hline $31-35$ years & 2 & 10.00 & 2 & 10.00 \\
\hline $36-40$ years & 6 & 30.00 & 2 & 10.00 \\
\hline $41-60$ years & 6 & 30.00 & 8 & 40.00 \\
\hline \multicolumn{5}{|l|}{ Education } \\
\hline Prathom 6 & 1 & 5.00 & 1 & 5.00 \\
\hline Mathayom 3 & 1 & 5.00 & 1 & 5.00 \\
\hline Mathayom 6 & 1 & 5.00 & 1 & 5.00 \\
\hline $\begin{array}{l}\text { Vocational } \\
\text { diploma }\end{array}$ & 2 & 10.00 & 2 & 10.00 \\
\hline Undergraduate & 12 & 60.00 & 12 & 60.00 \\
\hline Graduate & 3 & 15.00 & 3 & 15.00 \\
\hline
\end{tabular}

(20 participants). The sample comprised unequal number of male to female participants; a number of male $(15 \%)$ and female $(85 \%)$ participants in the target group whereas a number of male (5\%) and female (95\%) subjects in the control one. The mean age of participants was 35.85 years $(\mathrm{SD}=3.46)$ for both groups. A total of 60.0 percent had an undergraduate educational level in both control $(60 \%)$ and target $(60 \%)$ groups.

\section{Phochong chanting in control group}

Table 4 shows the comparison between before and after listening to Phochong chanting in the control group. There were statistical significance differences between before and after listening to Phochong chanting $(\mathrm{t}(39)=2.63 ; p=0.02)$. The stress indicator after listening to Phochong chanting 
(2.05 \pm 0.69$)$ showed lower compared to before listening (2.45 \pm 0.61$)$ (Figure 1). Matrix table of the Thai Stress Test index between before and after listening to Phochong chanting in the control group is also shown in Table 5.

The stress level assessed by the Thai Stress Test of all twenty participants in the control group were compared between before and after listening to Phochong chanting. Five participants were found to have lower number in the mild stress level after listening to Phochong chanting compared to their stress level scores before listening to Phochong chanting (seven participants). In addition, one participant went from 'normal mental health' to 'excellent mental health,' while three participants were found to have higher number in the 'excellent mental health' (Table 6, Figure 2 and Figure 3).

Table 7 compared the stress indicator between before and after seeing the Buddha image while listening to Phochong

Table 4: Stress indicator before and after
listening to Phochong chanting
\begin{tabular}{lcccccc}
\hline Stress Indicators & $\boldsymbol{n}$ & Mean & SD & t & $\boldsymbol{p}$ \\
\hline Before Listening & 20 & 2.45 & 0.61 & 2.63 & $0.02^{*}$ \\
After Listening & 20 & 2.05 & 0.69 & & \\
\hline * $P<0.05$
\end{tabular}

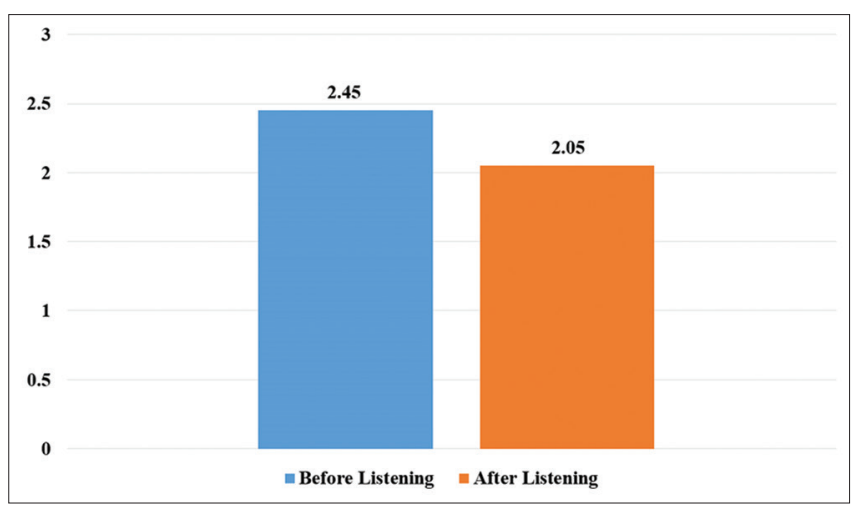

Figure 1: Stress indicator comparing between before and after listening to Phochong chanting in the control group

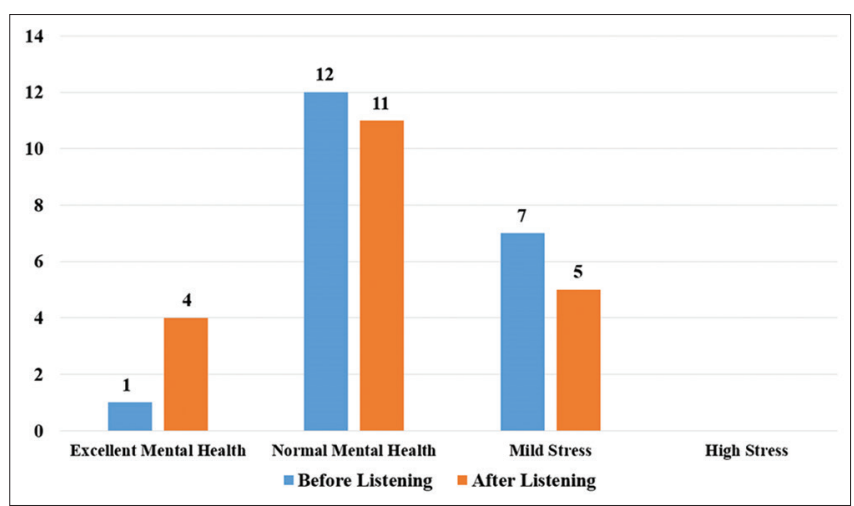

Figure 2 : Stress indicators assessed by Thai Stress Test comparing between before and after listening to Phochong chanting chanting in the target group. There were statistical significance differences of stress indicator comparing between before and after seeing the Buddha image while listening to Phochong chanting $(\mathrm{t}(39)=3.20 ; p=0.005)$. The stress indicator after seeing the Buddha image while listening to Phochong chanting (2.35 \pm 0.67$)$ showed lower level compared to before seeing the Buddha image while listening to Phochong chanting $(2.70 \pm 0.47)$. Matrix table of the Thai Stress Test index between before and after seeing the Buddha image while listening to Phochong chanting in target group is also shown in Table 8 and Figure 4.

The stress level assessed by the Thai Stress Test of all twenty participants were compared between before and after seeing Buddha image while listening to Phochong chanting in the target group. Five participants were found to have lower number in the mild stress level after seeing the Buddha image compared to their stress level before seeing Buddha image (fourteen participants). In addition, two participants went from 'normal mental health' to 'excellent mental health,' while three participants were found to have higher number in the 'normal mental health' (Table 9, Figure 5 and Figure 6).

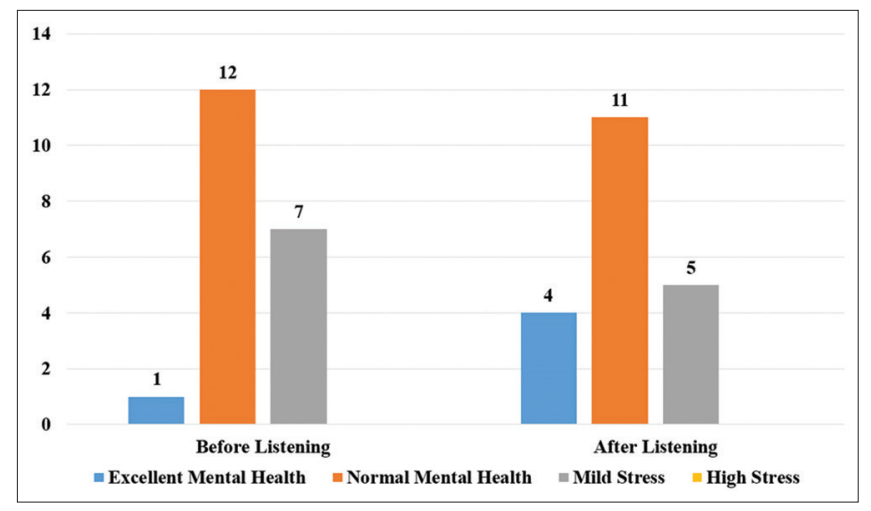

Figure 3: Stress indicators assessed by Thai Stress Test comparing between before and after listening to Phochong chanting in target group

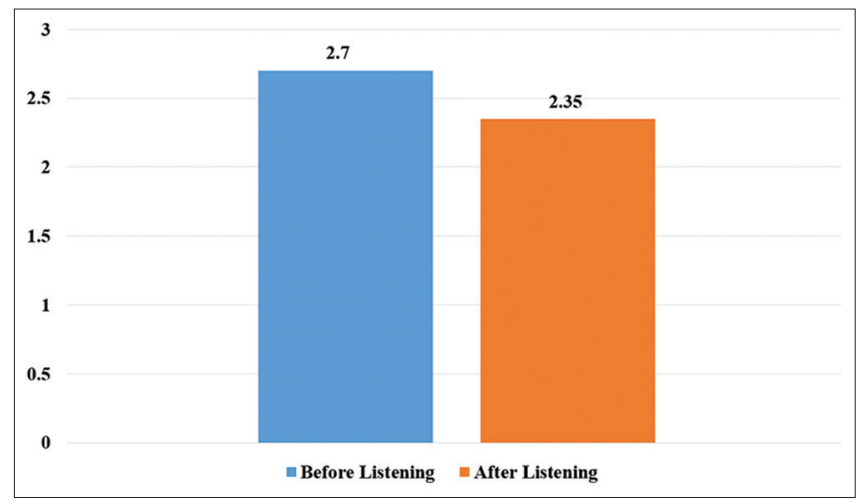

Figure 4: Stress indicators comparing between before and after seeing Buddha image while listening to Phochong chanting in the target group 
Table 5: Matrix table of the Thai Stress Test index

\begin{tabular}{|c|c|c|c|c|c|c|c|c|}
\hline \multirow[t]{2}{*}{ Subjects } & \multicolumn{4}{|c|}{ Before listening } & \multicolumn{4}{|c|}{ After listening } \\
\hline & $\begin{array}{l}\text { Positive } \\
\text { Scale }\end{array}$ & $\begin{array}{l}\text { Negative } \\
\text { scale }\end{array}$ & $\begin{array}{l}\text { Score } \\
\text { group }\end{array}$ & $\begin{array}{l}\text { Stress } \\
\text { indicator }\end{array}$ & $\begin{array}{l}\text { Positive } \\
\text { scale }\end{array}$ & $\begin{array}{l}\text { Negative } \\
\text { scale }\end{array}$ & $\begin{array}{l}\text { Score } \\
\text { group }\end{array}$ & $\begin{array}{l}\text { Stress } \\
\text { indicator }\end{array}$ \\
\hline 1 & 36 & 3 & 2 & Normal & 36 & 1 & 1 & Excellent \\
\hline 2 & 34 & 2 & 2 & Normal & 34 & 1 & 1 & Excellent \\
\hline 3 & 30 & 8 & 5 & Mild stress & 36 & 1 & 1 & Excellent \\
\hline 4 & 20 & 9 & 5 & Mild stress & 28 & 3 & 2 & Normal \\
\hline 5 & 17 & 6 & 4 & Normal & 24 & 2 & 2 & Normal \\
\hline 6 & 30 & 7 & 4 & Normal & 28 & 7 & 4 & Normal \\
\hline 7 & 20 & 2 & 2 & Normal & 16 & 0 & 1 & Excellent \\
\hline 8 & 14 & 14 & 5 & Mild stress & 16 & 13 & 5 & Mild stress \\
\hline 9 & 26 & 3 & 2 & Normal & 24 & 3 & 2 & Normal \\
\hline 10 & 26 & 2 & 2 & Normal & 28 & 3 & 2 & Normal \\
\hline 11 & 11 & 18 & 6 & Mild stress & 14 & 11 & 5 & Mild stress \\
\hline 12 & 32 & 4 & 3 & Normal & 36 & 2 & 2 & Normal \\
\hline 13 & 20 & 12 & 5 & Mild stress & 34 & 12 & 5 & Mild stress \\
\hline 15 & 22 & 4 & 3 & Normal & 32 & 2 & 2 & Normal \\
\hline 16 & 30 & 4 & 3 & Normal & 31 & 2 & 2 & Normal \\
\hline 17 & 7 & 8 & 7 & High stress & 23 & 6 & 4 & Mild stress \\
\hline 18 & 30 & 5 & 3 & Normal & 30 & 5 & 3 & Normal \\
\hline 19 & 26 & 12 & 5 & Mild stress & 22 & 7 & 4 & Normal \\
\hline 20 & 24 & 10 & 5 & Mild stress & 26 & 10 & 5 & Mild stress \\
\hline
\end{tabular}

\begin{tabular}{lcc}
$\begin{array}{l}\text { Table 6: Stress indicators assessed by Thai } \\
\text { Stress Test comparing between before and after } \\
\text { listening to Phochong chanting }\end{array}$ \\
\hline Stress indicator & Before listening & After listening \\
\hline Excellent mental health & 1 & 4 \\
Normal mental health & 12 & 11 \\
Mild stress & 7 & 5 \\
High stress & - & - \\
\hline
\end{tabular}

\begin{tabular}{|c|c|c|c|c|c|}
\hline Stress indicator & $n$ & Mean & SD & $\mathbf{t}$ & $p$ \\
\hline Before seeing & 20 & 2.70 & 0.47 & 3.20 & $0.005^{\star *}$ \\
\hline After seeing & 20 & 2.35 & 0.67 & & \\
\hline
\end{tabular}

The results of the Thai Stress Test scores of both control and target groups after listening to Phochong chanting showed that eleven participants (55\%) felt normal mental health, five participants (25\%) with mild stress, and four participants (20\%) at an excellent mentalhealth, respectively. The number of participants with excellent mental health was highest among the target group (20\%) (Table 10).

\section{DISCUSSION}

In this study, all participants were asked to rate their subjective feelings, which reflected only their current level of

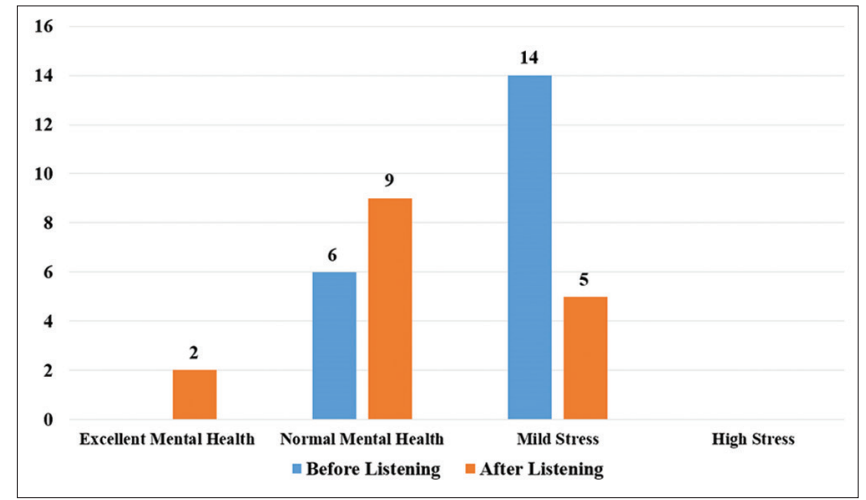

Figure 5: Stress indicators assessed by Thai Stress Test comparing between before and after seeing the Buddha image while listening to Phochong chanting

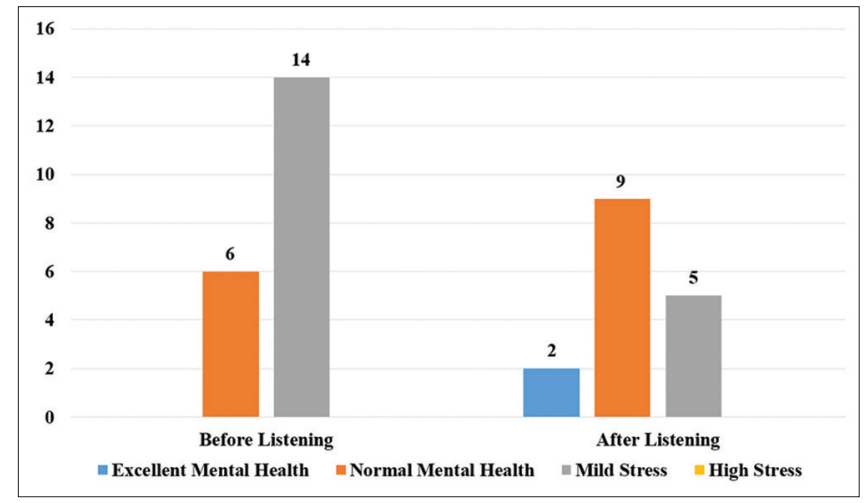

Figure 6: Stress indicators assessed by Thai Stress Test comparing between before and after seeing the Buddha image while listening to Phochong chanting

stress assessed by the Thai Stress Test. The Thai Stress Test was chosen as the instrument to measure stress level in this 


\begin{tabular}{|c|c|c|c|c|c|c|c|c|}
\hline \multirow[t]{2}{*}{ Participants } & \multicolumn{4}{|c|}{ Before seeing image } & \multicolumn{4}{|c|}{ After seeing image } \\
\hline & $\begin{array}{l}\text { Positive } \\
\text { scale }\end{array}$ & $\begin{array}{l}\text { Negative } \\
\text { scale }\end{array}$ & Score group & $\begin{array}{l}\text { Stress } \\
\text { indicator }\end{array}$ & $\begin{array}{l}\text { Positive } \\
\text { scale }\end{array}$ & $\begin{array}{l}\text { Negative } \\
\text { scale }\end{array}$ & Score group & $\begin{array}{l}\text { Stress } \\
\text { indicator }\end{array}$ \\
\hline 1 & 13 & 9 & 5 & Mild stress & 14 & 9 & 5 & Mild stress \\
\hline 2 & 29 & 2 & 2 & Normal & 36 & 1 & 1 & Mild stress \\
\hline 4 & 22 & 10 & 5 & Mild stress & 32 & 12 & 5 & Mild stress \\
\hline 5 & 34 & 7 & 4 & Normal & 36 & 4 & 3 & Normal \\
\hline 6 & 36 & 8 & 5 & Mild stress & 36 & 4 & 3 & Normal \\
\hline 7 & 28 & 7 & 4 & Normal & 23 & 7 & 4 & Normal \\
\hline 8 & 25 & 8 & 5 & Mild stress & 22 & 9 & 5 & Mild stress \\
\hline 9 & 20 & 11 & 5 & Mild stress & 22 & 11 & 5 & Mild stress \\
\hline 10 & 16 & 8 & 5 & Mild stress & 23 & 5 & 3 & Normal \\
\hline 12 & 30 & 6 & 4 & Normal & 32 & 6 & 4 & Normal \\
\hline 13 & 28 & 12 & 5 & Mild stress & 30 & 3 & 2 & Normal \\
\hline 14 & 28 & 8 & 5 & Mild stress & 24 & 7 & 4 & Normal \\
\hline 15 & 22 & 11 & 5 & Mild stress & 30 & 12 & 5 & Mild stress \\
\hline 16 & 34 & 12 & 5 & Mild stress & 36 & 12 & 5 & Mild stress \\
\hline 17 & 30 & 16 & 5 & Mild stress & 28 & 16 & 5 & Mild stress \\
\hline 18 & 21 & 4 & 3 & Normal & 25 & 2 & 2 & Normal \\
\hline 19 & 28 & 2 & 2 & Normal & 34 & 1 & 1 & Excellent \\
\hline 20 & 30 & 13 & 5 & Mild stress & 22 & 11 & 5 & Mild stress \\
\hline
\end{tabular}

\begin{tabular}{|c|c|c|}
\hline Stress indicator & Before Listening & After Listening \\
\hline Excellent mental health & - & 2 \\
\hline Normal mental health & 6 & 9 \\
\hline Mild stress & 14 & 9 \\
\hline Stressful & - & - \\
\hline
\end{tabular}

Table 10: Stress indicators assessed by Thai Stress Test after listening to Phochong chanting

\begin{tabular}{lcc}
\hline Stress indicator & Control group & Target group \\
\hline Excellent mental health & 2 & 4 \\
Normal mental health & 9 & 11 \\
Mild stress & 9 & 5 \\
Stressful & - & - \\
\hline
\end{tabular}

study. The main reason in choosing this instrument, although it is a relatively new and still a not widely used instrument, was to reduce problems concerning cultural and language barriers, since the instrument was developed specifically to measure stress in Thai people. ${ }^{6}$ The Thai Stress Test is thus a screening instrument for stressed people, so it is probable that a higher percentage of participants with stress detected in this study than in other studies. In addition, the Thai Stress Test has adequate reliability, adequate construct validity, and sufficient discriminant power. The result assessed by the Thai Stress Test in this study will then be a more direct and meaningful application to detect mental health illness. ${ }^{6}$

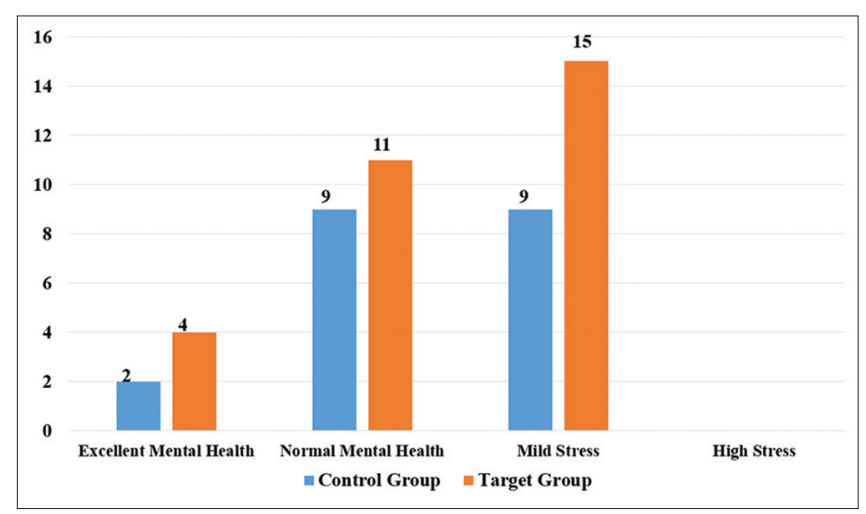

Figure 7: Stress indicators assessed by Thai Stress Test after listening to Phochong chanting

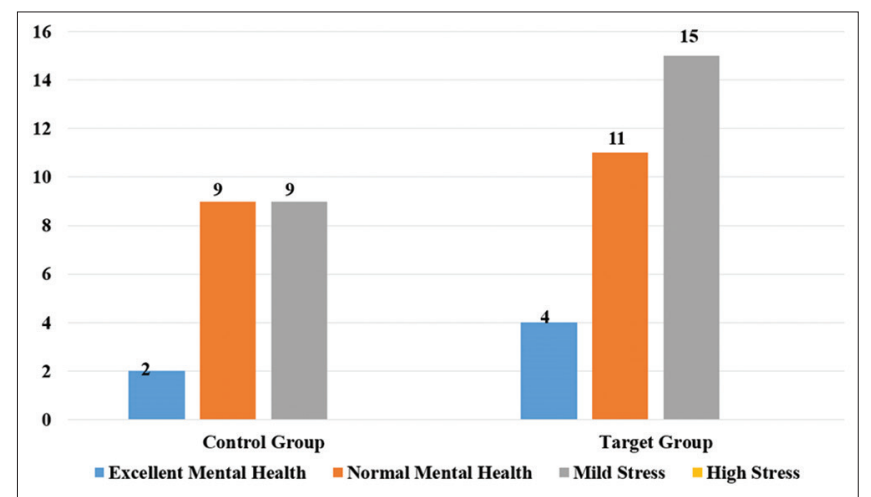

Figure 8: Stress indicators assessed by Thai Stress Test after listening to Phochong chanting

Stress is the psychological and physical state that results when the resources of the individual are not sufficient to cope up 
with the demands and pressure of the situation. ${ }^{27}$ It usually results in negative thoughts and perceptions which affects even their day to day life. Similar to a previous study, ${ }^{18}$ the framework upon which this research was based Buddhist doctrine. According to the previous studies, Buddhism views illness as an imbalance between the body and mind. 15,18,20,28,29 This imbalance can lead to suffering (i.e., discomfort or stress) and a decreased sense of peacefulness. ${ }^{16}$ Buddhist meditation then appears to serve as a catalyst for self-healing by restoring and balancing the interaction between one's mind and body. ${ }^{18,30}$ When stress begins, muscles constrict and the respiratory rate increases, consuming metabolic energy. ${ }^{18}$ Moreover, Buddhist meditation had an influence on the stress levels and blood pressure readings of the hypertensive participants. ${ }^{18}$ Saelo and colleagues stated that the peacefulness experienced by these individuals, as a result engagement in Buddhist meditation, may have been the result of beta endorphin production in the hypothalamus. ${ }^{18}$ In addition, beta endorphins have a morphine-like characteristic that can have a positive effect on mood (i.e., peacefulness and calmness) ${ }^{20} \mathrm{~A}$ peaceful state of mind (i.e., reduced stress) can stimulate functioning of the parasympathetic nervous system which results in a decrease in heart rate, dilation of the peripheral blood vessels and improvement in blood flow. ${ }^{20-21}$ All of these factors can finally lead to a reduction of one's blood pressure. ${ }^{18}$

Achterberg and colleagues ${ }^{29}$ additionally stated that according to a Buddhist perspective, mankind confronts distress at all times because of the "Three Characteristics of Existence' (tilakkkhana): impermanence (anicca); suffering (dukha); and, no-self (anatta), respectively. ${ }^{18}$ However, humans can decrease or eliminate their suffering or distress by practicing Buddhist meditation. ${ }^{18}$ It helps establish cheerfulness (pramod), joy (piti), pleasure (sukha) and concentration (Samadhi), all which appear to stimulate the parasympathetic nervous system. ${ }^{18}$ Previous studies showed that stimulation of the parasympathetic nervous system could lead to a decrease in heart rate, dilatation of peripheral blood vessels and improvement in blood flow, which, subsequently, causes a decrease in blood pressure. ${ }^{18,20,21}$ Engaging in Buddhist meditation cultivates concentration and positive mindfulness that can facilitate a decrease in the sense of suffering and an increase in a sense of calm. Positive mindfulness appears to stimulate the parasympathetic nervous system, which, in turn, leads to a decreased heart rate, dilation of the peripheral blood vessels and improved blood flow. ${ }^{19}$ These factors, subsequently, contribute to reduction in one's blood pressure. ${ }^{20,21}$ The fact that Buddhist meditation had an influence on the stress levels and blood pressure readings of the hypertensive participants is consistent with prior findings. Regardless of the type of meditation practice used, prior studies have found when meditation is performed, for 10 to 45 minutes at least once to twice daily for six weeks or more, there tends to be a decrease in both the systolic and diastolic blood pressure readings, ${ }^{23-26,31}$ and levels of stress. ${ }^{23,31}$ Prior research has found that meditation decreases systolic and diastolic blood pressure, ${ }^{23-26,31}$ heart rate, ${ }^{24,25}$ stress, ${ }^{23,31}$ and the use of antihypertensive medications. ${ }^{26}$

However, the present study had limitations that need to be taken into consideration. This limitation is quite difficult to avoid because that is the way most stress measurement is designed. Therefore, the stress status measured should represent the natural level of stress of the participants. Additionally, all participants were Buddhists and had a low to middle socio-economic level. This experimental design may not be applicable to individuals from other religions, cultures or socio-economic levels. Because of the small number of participants, no inferential statistics could be done to demonstrate if any of the changes in stress levels or mindfulness levels were statistically significant. Thus, the findings of the evaluation of stress level must be used with great caution. Using a much larger participant sample size is recommended for future study. In addition, a sufficient number of measurements regarding stress, mindfulness and blood pressure need to be obtained so that inferential statistics can be used in the determination of whether Phochong Chanting actually has a statistically significant impact on one's stress level, mindfulness and blood pressure. Finally, this study did not investigate participants' coping mechanisms.

Future research should be conducted on the implementation and evaluation of the using a much larger participant sample size. In addition, future studies need to obtain a sample from other chanting, similar to the one used in the present study; for example, Chinabunchorn Chanting. Finally, with future implementation and evaluation studies, that use other Chanting, a sufficient number of measurements regarding stress, mindfulness and blood pressure need to be obtained so that inferential statistics can be used in the determination of whether Chanting actually has a statistically significant impact on one's stress level and mindfulness and blood pressure.

\section{CONCLUSION}

Findings of this study indicated that psychological morbidity was common in all participants. By listening chanting during any activities would help the stress level reduction. Further studies based on larger sample sizes are recommended to explore consequences and describe this phenomenon.

\section{DISCLOSURE}

The authors report no conflicts of interest in this work. 


\section{ACKNOWLEDGEMENT}

We thank all of the participants who involved in this study as main data provider.

\section{REFERENCES}

1. Webster's ninth new collegiate dictionary. NeXT digital ed., Springfield, MA: Merriam-Webster, 1988.

2. Taylor S. Health psychology. New York: Ramdon House, 1986.

3. Sani M, Mahfouz MS, Bani I, Alsomily AH, Alagi D, Alsomily NY, et al. Prevalence of stress among medical students in Jizan University, Kingdom of Saudi Arabia. Gulf Medical Journal 2012; 1(1): 19-25.

4. Mahajan AS. Stress in Medical Education: a global issue or Much Ado about nothing specific? South-East Asian. Journal of Medical Education 2010; 4(2): 9-13.

5. Ganjanapan S. Webster's definition urban community, 1981. Retrieved From http://www.human.cmu.ac.th

6. Phattharayuttawat S, Ngamthipwattana T and Sukhatungkha K. The developmentof the Thai Stress Test. Journal of Psychiatric Association of Thailand 2000; 45(3): 238-250

7. Shariati M, Yunesian M and Vash JH. Mental health of medical students: a cross-sectional study inTehran. Psycholo Repo 2007;100:346-354.

8. Dyrbye LN, ThomasMR and Shanafelt TD. Medical students distress: causes, consequences and proposedsolutions. Mayo Clin Proc 2005;80:1613-1522.

9. Baldwin DC, Steven R, Daugherty, Edward J and Eckenfels. Student perceptions ofmistreatment and harassment during medical school - a survey of 10 United Statesschools. West J Med 1991;155:140-145.

10. Sreeramareddy CT, Shankar PR, Binu VS, Mukhopadhyay C, Ray B and Menezes RG. Psychological morbidity, sources of stress and coping strategies among under graduatemedical students of Nepal. BMC Med Educ 2007;7:26.

11. Ko SM, Kua EH and Fones CS. Stress and the undergraduates. Singapore Med J1999;40:627-630.

12. Selye H. The stress of life. New York: McGraw-Hill, 1959.

13. Glaister JA. Healing: Analysis of the concept. International Journal of Nursing Practice 2001;7:63-68.

14. Hatthakit $U$, Parker M and Niyomthai $N$. Nurses' experience in integrating complementary therapies into nursing practice. Thai Journal of Nursing Research 2004; 8(2): 126-143.

15. Erickson HL. Philosophy and theory of holism. Nursing Clinics North America 2007; 42: 39-63.

16. Lindberg DA. Integrative review of research related to meditation, spirituality and the elderly. Geriatric Nursing 2005; 26: 372-377.

17. Bonadonna R. Meditation's impact on chronic illness. Holistic Nursing Practice 2003;17:309-319.

18. Saelo J, Hatthakit $U$ and Nilmanat K. Development and Evaluation of a Self-Healing Nursing Model using Buddhist Meditation to Treat Hypertension. Pacific Rim International Journal of Nursing Research 2012;16(1): 64-77.

19. Maier-Lorentz MM. The importance of prayer for mind/body healing. Nursing Forum 2004; 39: 23-32.

20. Dossey BM, Keegan L and Guzzetta CE. Holistic nursing. Sudbury (MA): Jones \& Bartlett Publishers, 2005.

21. Monacha R. Why meditation? Australian Family Physician 2000; 29: 1135-1138.

22. Alexander CN, Schneider RH, Staggers F, Sheppard W, Clayborne BM, Rainforth M, et al. Trial of stress reduction for Hypertension in older African Americans: Sex and risk subgroup analysis. Hypertension1996; 28(2): 228-237.

23. Barnes VA, Treiber FA and Davis HC. Impact of transcendental meditation on cardiovascular function at rest and during acute stress in adolescents with high normal blood pressure. Journal of Psychosomatics Research2001; 51: 597-605.

24. Barnes VA, Treiber FA and Johnson MH. Impact of transcendental meditation on ambulatory blood pressure in African-American adolescents. American Journal of Hypertension 2004;17:366-369.

25. Manikonda P, Stoerk S, Toegel S, Schardt F, Angermann C, Gruenberger I, et al. Influence of non-pharmacological treatment (contemplative meditation and breathing technique) on stress induced hypertension: A randomized controlled study. American Journal of Hypertension 2005; 18(5): 89A-90A.

26. Schneider $\mathrm{RH}$, Alexander $\mathrm{CN}$, Straggers $\mathrm{F}$, Orme-Johnson DW, Rainforth M, Salerno JW, et al. Randomized controlled trial of stress reduction on Africans treated for hypertension for over one year. American Journal of Hypertension 2005; 18(1): 88-98.

27. Michie S. Causes and management of stress at work. Occup Environ Med 2002;59:67-72.

28. Buddhadhamma P. Natural laws and values for life. Albany (NY): State University of New York Press, 1995.

29. Achterberg J, Dossey L, Gordon JS, Hegedus C, Heremann MW and Nelson R. Mind-body intervention, 2006. [online.. Retrieved from: http://www.naturalhealthvillage.com/reports/rpt2oam/ mindbody.htm

30. Waldspurger-Robb WJ. Self-healing: A concept analysis. Nursing Forum2003; 41: 60-77.

31. Theera-apisakkul $J$ and Lueboonthavatchai $P$. Quality of Life and Associated Psychosocial Factors of Non-Insulin Dependent Diabetes Mellitus Patients in Somdejphraputthalertla Hospital, Samutsongkram Province, Journal of the Psychiatric Association of Thailand 2009; 54(2): 185-196.

\footnotetext{
Authors Contribution:

JK-Concept and design of the study, statistically analyzed and interpreted; JR-Concept and design of the study; KW-Concept and design of the study;

PS-Concept and design of the study, manuscript preparation, statistically analyzed and interpreted, critical revision of the manuscript.

Work attributed to:

Brain Science and Engineering Innovation Research Group, School of Anti-Aging and Regenerative Medicine, Mae Fah Luang University, Bangkok 10110

Thailand.

Orcid ID:

Dr. Jidapa Kerdsurivong-(D) https://orcid.org/0000-0002-5428-3523

Dr. Jarasphol Rintra-10 https://orcid.org/0000-0001-5079-0213

Dr. Karnt Wongsuphasawat-10 https://orcid.org/0000-0001-6570-0663

Dr. Phakkharawat Sittiprapaporn-(i) https://orcid.org/0000-0002-4103-9396

Source of Support: Brain Science and Engineering Research Group, Mae Fah Luang University (MFU-Grant), Thailand. Conflict of Interest: None.
} 